\title{
As relações entre a Índia e Moçambique: uma parceria estratégica (1947-2019)
}

\author{
Relations between India and Mozambique: a strategic partnership (1947 -2019)
}

DOI: https://doi.org/10.22456/2178-8839. 113081

Jacqueline A. Haffner Universidade Federal do Rio Grande do Sul, Porto Alegre, Brasil jacqueline.haffner@ufrgs.br

Hetalben H. Patel Universidade Joaquim Chissano, Maputo, Moçambique bena.patel84@gmail.com

\begin{abstract}
Resumo
O presente artigo tem como tema Índia como parceiro estratégico de Moçambique. O principal objectivo do trabalho é a descrição e análise da evolução das relações bilaterais entre Índia e Moçambique e, demonstrar como a Índia tornou-se num parceiro estratégico de Moçambique. Para tal, o artigo primeiro descreve o início das relações diplomáticas e seus contornos até os dias de hoje. De seguida é exposto o crescimento das relações comerciais e por fim são apresentados os investimentos feitos pela Índia em Moçambique, principalmente no sector de gás natural. A pesquisa é exploratória e o método de análise utilizado foi o método histórico. A principal hipótese está relacionada com os crescentes interesses geoestratégicos da Índia pelos recursos energéticos e acesso ao Oceano Índico, que a leva estreitar laços com os estados africanos e fazer aliança estratégica com Moçambique. O artigo traz como principais resultados as evidências de como o aprofundamento das relações econômicas, políticas e de segurança fez com que a Índia passasse a ser um parceiro estratégico para Moçambique.
\end{abstract}

Palavras-chave: Moçambique; Índia; Relações bilaterais;

\section{Abstract}

The present article has as its theme India as a strategic partner of Mozambique. The main objective of the work is to describe and analyze the evolution of bilateral relations between India and Mozambique and to demonstrate how India has become a strategic partner for Mozambique. To this end, the article first describes the beginning of diplomatic relations and their outlines until today. Next, the growth of commercial relations is exposed and, finally, the investments made by India in Mozambique, mainly in the natural gas sector, are presented. The methods of analysis used we re the comparative method and the historical method. The main hypothesis is related to India's growing geostrategic interests in energy resources and access to the Indian Ocean, which leads it to strengthen ties with African states and make a strategic alliance with Mozambique. The article brings as main results the evidences of how the deepening of the economic, political and security relations made India a strategic partner for Mozambique.

Keywords: Mozambique; India; Bilateral relations; 


\section{Introdução}

A Índia emergiu no séc. XXI como um actor económico global importante bem como político e considerado como um parceiro importante para vários países Africanos. De acordo com Bussière e Mehl (2008), desde o fim da segunda guerra mundial a economia global tem crescido acompanhado pela mudança nos padrões de comércio, que por sua vez reflecte nas mudanças da estrutura da economia global. Estas mudanças incluem o surgimento de blocos regionais de comércio, desindustrialização ${ }^{1}$ em várias economias avançadas, a crescente participação dos países da Europa do Leste e a emergência da Índia e China. Os países recentemente industrializados como Índia têm aumentad o dramaticamente sua quota no comércio mundial e a sua quota de exportações de produtos manufacturados.

Com o crescimento da economia, a Índia projecta um maior engajamento internacional. O interesse geopolítico da Índia mudou claramente com a crescente necessidade de recursos energéticos e mercados. E, ainda mais importante, tornou-se o acesso ao OceanoÍndico, uma vez que a maior parte dos seus recursos energéticos passam por este Oceanoe, pela mesma exporta seus produtos. Quer-se dizer com isso que os Estados Africanos outrora parceiros históricos, hoje tornaram-se estratégicos para a Índia, como é o caso de Moçambique.

As relações bilaterais entre Moçambique e Índia iniciam imediatamente após a independência de Moçambique. $\mathrm{Na}$ época a Índia foi um dos primeiros países a abrir a sua missão diplomática no país. No entanto, as relações entre estes dois países possuem uma história longínqua. A presença do povo indiano já se fazia sentir em Moçambique mesmo antes da chegada dos colonizadores no continente Africano.

Percebe-se que desde o período colonial a Índia promoveu a imigração para o território Moçambicano colonizado por Portugal, esta presença secular indiana no continente africano deixou em Moçambique o legado da sexta maior diáspora Indiana com cerca de 25 mil cidadãos de origem Indiana (FREY, 2017). Já na época da luta de libertação, a Índia providenciou apoio a vários países Africanos incluindo Moçambique.

A cooperaçãobilateral iniciada no ano de 1975 passou a ter maior robustez no séc. XXI com “boom” económico que a Índia passou a ter e a descoberta de grandes reservas de gás natural em Moçambique. Assim, verifica -se actualmente grandes investimentos indianos em Moçambique e aumento no volume do comércio bilateral. Para além das relações económicas demonstrarem resultantes promissores, a cooperação entre os dois países vai sendo promovida pela assinatura de acordos bilaterais na área de segurança, agricultura, energia, infra-estruturas entre outras.

A pergunta de pesquisa associada a este artigo é:É Moçambique é um parceiro estratégico para a Índia? O presente artigo tem como tema Índia como parceiro estratégico de Moçambique. O principal objectivo do trabalho é a descrição e análise da evolução das relações bilaterais entre Índia e Moçambique e, demonstrar como a Índia tornou -se num parceiro estratégico de Moçambique. Para tal, o artigo primeiro descreve o início das relações diplomáticas e seus contornos até os dias de hoje. De seguida é exposto o crescimento das relações comerciais e por fim são apresentados os investimentos feitos pela Índia em Moçambique, principalmente no sector de gás natural. A pesquisa é expl oratória e o método de análise utilizado foi o método histórico. A principal hipótese está relacionada com os crescentesinteresses geoestratégicos da Índia pelos recursos energéticos e acesso ao Oceano Índico, que a leva estreitar laços com os estados africanos e fazer aliança estratégica com Moçambique. $\mathrm{O}$ artigo traz como principais resultados as evidências de como o aprofundamento das relações econômicas, políticas e de segurança fez com que a Índia passasse a ser um parceiro estratégico para Moçambique

No que toca ao embaçamento teórico, o trabalho apoia-se na teoria de Interdependência que surge na década 1970, liderada por Robert Keohane e Joseph Nye (1977). Esta teoria explicaria as relações entre Moçambique e a Índia que utiliza o conceito da interdependência para criar um paradigma analítico que superasse o paradigma realista,. Para estes autores a interdependência refere-se a situações caracterizadas por efeitos recíprocos entre países ou entre actores em diferentes países. A teoria da interdependência veio contrariar as principais assumpções analíticas do realismo. Neste

${ }^{1}$ Processo de eliminação ou redução da capacidade industrial em um país ou região, especialmente a industria pesada ou transfor madora 
modelo, os Estados não são os únicos actores importantes, os actores transnacionais são igualmente intervenientes importantes nas Relações Internacionais. Empresas, Organizações Não Governamentais (ONGs) e indivíduos podem e devem ter influência na política mundial (De SOUSA, 2005, p. 204).

O presente artigo está dividido em quatro partes. A primeira parte apresenta o início e evolução das relações entre Índia e Moçambique. A segunda parte por sua vez destaca a expansão do comércio bilateral. A terceira parte identifica diferentes investimentos indianos em Moçambique dentre os quais o sector extractivo e não-extractivo. Por fim, a última parte refere a cooperação no sector de segurança que tem ganhado mais ímpeto nos últimos anos entre os dois países.

\section{O estabelecimento de relações diplomáticas entre Índia e Moçambique}

A Índia sempre manteve um relacionamento cordial e firme desde a sua independência (1947) com os estados africanos. Logo após a sua independência, a Índia engajou-se no apoio a luta contra o colonialismo através do Movimento dos País Não-Alinhados (MPNA) sob a administração Nehru e Indira Gandhi e, Moçambique foi um destes espaços do exercício de solidariedade. A ajuda da Índia era facilitada através dos países vizinhos de Moçambique já independentes como caso da Tanzânia e Quénia.

Após a conquista da independência por parte de Moçambique, a Índia foi um dos primeiros países a abrir a sua representação diplomática na capital do país logo em 1975. No entanto, com o início da guerra civil em 1976, a cooperação bilateral entre Moçambique e Índia limitava-se essencialmente a aspectos de natureza político-diplomática, nomeadamente acções diplomáticas coordenadas para o isolamento da Rodésia do Sul e do regime do Apartheid. Assim, com o término da guerra civil em 1992 e, com a introdução do liberalismo económico, Moçambique abriu a sua representação em Nova Deli no ano de 2001 (ALTO COMISSARIADO DA ÍNDIA, 2020).

Entretanto, é importante destacar que o período da guerra fria não permitiu que as relações entre os dois países se fortificassem pois, havia o contexto do conflitobipolar onde alguns estados africanos como caso de Moçambique ainda estavam sob jugo colonial e outros vivam uma guerra civil. No entanto, mesmonestas dificuldades todas, a Índia inicia a sua aproximação através do MPNA e apoio aos movimentos de luta anti-colonial. Portanto, Moçambique contou não somente com o apoio da diáspora indiana em seu território mas também do apoio directo da Índia para a sua independência.

Foi o final da guerra fria que permitiu o "renascimento" das relações entre a Índia e os estados africanos. Tanto a Índia como Moçambique introduziram reformas pela adopção de economia de mercado aberto com as políticas neoliberais como a privatização, reduzida participação do estado na economia, livre circulação de capitais internacionais bem como a redução do proteccionismo económico e pode-se dizer que este novo enfoque económico aproximou os dois países.

Será preciso referenciar que apesar do contexto da guerra fria, ocorreram algumas visitas oficiais de ambos lados como se pode observar no quadro1 abaixo:

Quadro1 - Visita de Chefes de Estado

\begin{tabular}{|c|l|l|}
\hline Ano & Visita de Chefe de Estado Moçambicano a Índia & Visita de Chefes de Estado Indiano a Moçambique \\
\hline 1982 & Samora Machel & Indira Gandhi \\
\hline 1988 e 2003 & Joaquim Chissano & \\
\hline 2010 & Armando Guebuza & \\
\hline 2015 & Filipe Nyusi (actual presidente) & \\
\hline 2016 & & Narendra Modi (Actual Primeiro-Ministro) \\
\hline
\end{tabular}

Fonte: elaborado pelas autoras a partir de dados obtidos Alto Comissariado Indiano (ALTO COMISSARIADO DA ÍNDIA, 2020). 
Após o final da guerra fria as relações bilaterais começam a crescer muito lentamente uma vez que a estrutura económica moçambicana havia sido completamente destruída com a guerra civil que durou 16 anos. $\mathrm{O}$ quadro 1 acima mostra a manutenção relações diplomáticas principalmente dolado moçambicano que teve todos seus chefes de estados a visitar Índia. Porém, do lado da Índia observa -se um grande vazio de 34 anos de visita entre seus representantes. Mas como será observado mais adiante, com a descoberta de reservas de gás, Moçambique torna -se relevante no xadrez energético mundial fazendo com que a primeira visita do actual primeiro-ministro indiano Narendra Modi, no seu primeiro períplo no continente africano, visitasse Moçambique em primeirolugar no ano de 2016.

Desta forma, Moçambique e Índia vêm assinando vários acordos bilaterais desde a sua independência e memorandos de cooperação em diversas áreas tais como: agricultura, desenvolvimento rural, pesquisa técnica e científica, protecção dos investimentos, retirada de dupla taxação dos seus cidadãos, pequenas e médias empresas, recursos minerais, óleo e gás natural e defesa e cooperação (ALTO COMISSARIADO DA ÍNDIA, 2020). Assim, para melhor compreender a evolução das relações bilaterais, apresenta -se de seguida o quadro 2 sobre os acordos e memorandos assinados entre os dois estados nos últimos dez anos:

\section{Quadro 2 - Lista dos Acordose Memorandos Entre Índia e Moçambique}

\begin{tabular}{|c|c|}
\hline Ano & Acordos e Memorandos \\
\hline 2010 & $\begin{array}{l}\text { Durante a visita de Estado do Presidente Armando Guebuza de Moçambique a Índia, três acordos foram assinados: } \\
\text { a) Memorando de Entendimento entre o Governo da Índia e o Governo de Moçambique sobre Cooperação nos campos } \\
\text { de Recursos Minerais; } \\
\text { b) Acordo para evitar dupla tributação (DTAA) entre Índia e Moçambique; } \\
\text { c) Memorando de entendimento sobre cooperação no campo das micro, pequenas e médias empresas (MPME) entre } \\
\text { o Ministério das Micro, Pequenas e Médias Empresas da Índia e o Ministério da Indústria e Comércio de Moçambique. }\end{array}$ \\
\hline 2012 & Assinatura do acordo na área de segurança que permite a Índia patrulhar as águas territoriais moçambicanas. \\
\hline 2014 & $\begin{array}{l}\text { Durante a visita do Ministro de Negócios Estrangeiros de Moçambique a Índia, foi assinado um Memorandum de } \\
\text { Entendimento para melhorar a cooperação na área de Gás natural e Petróleo. }\end{array}$ \\
\hline 2015 & $\begin{array}{l}\text { Assinatura de Memorando de Entendimento durante a visita do presidente de Moçambique a Índia sobre Cooperação no } \\
\text { campo das novas energias renováveis nomeadamente: Solar. Eólico, Biocombustível, Geotermal; }\end{array}$ \\
\hline 2016 & $\begin{array}{l}\text { Memorandos de Entendimento /Acordos assinados durante a visita do primeiro-ministro indiano a Moçambique: } \\
\text { a) Memorando de Entendimento entre a Índia e Moçambique sobre redução da demanda por drogas e prevenção do } \\
\text { tráfico ilícito de estupefacientes, substâncias psicotrópicas e produtos químicos precursores e assuntos relacionados } \\
\text { b) Memorando de Entendimento entre o Governo da Índia e o Governo de Moçambique na área de assuntos Juvenis } \\
\text { e desportivos. } \\
\text { c) Contrato de longo prazo para compra de leguminosas de Moçambique }\end{array}$ \\
\hline 2017 & Acordo entre Moçambique e Índia para acelerar o desenvolvimento da descoberta das reservas de gás. \\
\hline 2019 & the \\
\hline
\end{tabular}

Fonte: Elaborado pelas autoras a partir de dados obtidos do Ministério dos Negócios Estrangeiros da Índia (INDIA, 2015).

Importa aqui referir que o estabelecimento da missão diplomática moçambicana em Nova Deli (2001) levou ao aumento de cooperação seguido de acordos bilaterais. Outro momento marcantena aproximação das parcerias foi após a descoberta das enormes reservas de gás no território moçambicano. Os comités conjuntos de ambos países formados pelos técnicos de diferentes áreas tais como Económica, Cultural, Científica e de Cooperação técnica também ajudaram a avaliar e fomentar a parceria estratégica entre estes dois países.

\footnotetext{
${ }^{2}$ White shipping significa partilha e intercâmbio de informações no que toca a movimentos de navios comerciais.
} 
A assistência ao desenvolvimento tem sido outro pilar de cooperação da Índia para Moçambique onde a maior parte do suporte tem sido por via de linhas de crédito implementadas através do EXIM ${ }^{3}$ Bank of India. Outra componente da cooperação reside na pertença as diferentes Organizações internacionais pelos dois países tais como ONU, Commonwealth, Banco Mundial (BM), Fundo Monetário Internacional (FMI), Movimento dos Países Não-Alinhados (MPNA) e mais recentemente o Indian Ocean Rim Association (IORA).

Actualmente, com a descoberta de grandes reservas de gás no Norte de Moçambique, observa -se a assinatura de acordos na área de segurança energética e protecção do Oceano Índico. Outro sector também privilegiado tem sido a área da educação em forma de bolsas de estudo e formação técnica para os servidores públicos.

\section{Ampliação das Relações Comerciais}

A relação comercial entre Moçambique e Índia, apesar de secular, atravessou por muitos percalços que interferiram no ritmo do seu crescimento. A guerra fria e a guerra civil em Moçambique (1976-1992) abrandaram as relações políticas e económicas que por sua vezlevou muitos anos a recuperar-se. Actualmente o comércio bilateral goza de uma relação bastante activa principalmente a partir de 2015. Ainda mais, a Índia se encontra entre os cinco principais parceiros de Moçambique nos últimos anos, tanto a nível de importaçãobem como exportação. Para melhor compreender a evolução da relação comercial entre os dois países, apresenta -se de seguida o gráfico 1:

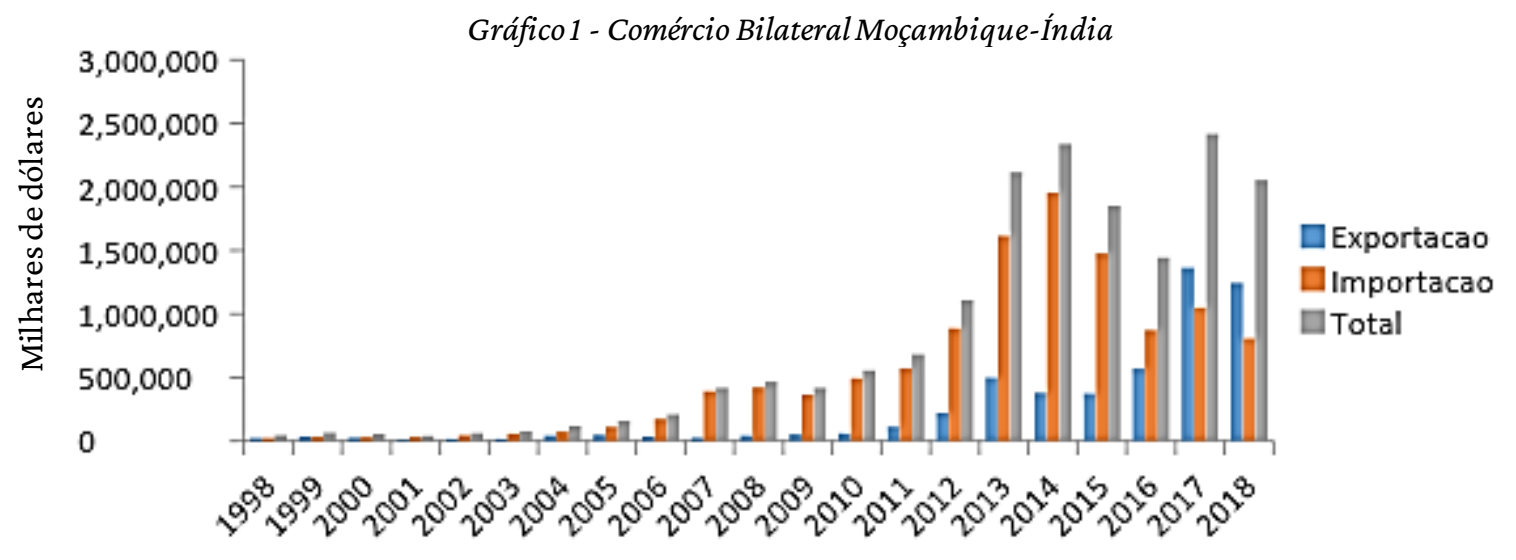

Fonte: Elaborado pelas autoras com base em dados obtidos no UNCTAD (2019).

O gráfico 1 possibilita verificar a evolução da balança comercial entre os dois países e, observa-se um crescimento gradual nos últimos dez anos (1998-2018). O gráfico também permite notar que o comércio bilateral atingiu mais de 2 biliões no ano de 2018 e que a balança comercial que era negativa para Moçambique, passou a ser positiva a partir do ano de 2017. Isto indica um marco importante na relação comercial entre os dois países e também ao nível do continente africano, onde a maioria dos estados apresenta uma balança comercial negativa em relação à Índia.

Pode-se ainda perceber pelo gráfico 1 que o comércio apresenta uma tendência de aumento das exportações para o lado Moçambicano partir do ano 2016, que foi também o ano da visita do actual primeiro min istro da Índia a Moçambique. Será importante mencionar que foi nesta visita que se observou a assinatura do acordo de produção e comercialização agrícola. E, como resultado, nos anos seguintes as exportações Moçambicanas superaram as importações da Índia. Referir ainda que os dois países mantêm troca de visitas constantes de grupos técnicos como apresentado. A assinatura de memorandos como diversificação e eliminação de taxas de produtos provenientes de Moçambique, com excepção de bebidas alcoólicas e tabaco também permitiu o aumento do comércio bilateral entre os dois países.

${ }^{3}$ Export-Import 
Como resultado do incremento do comércio bilateral entre Índia e Moçambique, verifica -se na tabela 1 a seguir, a posição da Índia entre os principais parceiros comerciais ocupando a posição de topo:

\begin{tabular}{|c|c|c|c|}
\hline Country & Export USDS & Country & Import USDS \\
\hline India & $\$ 1,435,777,689$ & South Africa & $\$ 1,772,616,966$ \\
\hline Netherlands & $\$ 1,102,933,247$ & China & $\$ 799,458,273$ \\
\hline South Africa & $\$ 895,879,582$ & United Arab Emirates & $\$ 518,874,355$ \\
\hline China & $\$ 301,889,298$ & Netherlands & $\$ 517,984,366$ \\
\hline Hong Kong & $\$ 124,153,255$ & India & $\$ 490,291,046$ \\
\hline Singapore & $\$ 115,804,531$ & Singapore & $\$ 282,317,915$ \\
\hline Poland & $\$ 101,433,272$ & Portugal & $\$ 230,421,811$ \\
\hline United States & $\$ 99,262,118$ & United States & $\$ 218,154,967$ \\
\hline United Kingdom & $\$ 93,266,013$ & Japan & $\$ 196,196,171$ \\
\hline United Arab Emirates & $\$ 74,064,217$ & Thailand & $\$ 158,085,729$ \\
\hline
\end{tabular}

Na coluna das exportações Moçambicanas, a tabela1 acima mostra que a Índia ocupa um lugar de topo em relação a china enquanto a China ocupa quartolugar. Em relação a importação, a China ocupa três posições acima da Índia estando em segundo lugar na lista dos parceiros comerciais, enquanto a Índia se encontra na quinta posição. Contudo, quando comparado em termos de balança comercial, observa-se que a Índia leva vantagem em relação a China pois, Moçambique apresenta uma balança comercial positiva com a Índia. No entanto, apesar das relações comerciais apresentam dados animadores, a mesma ainda é caracterizada pela dicotomia Norte-Sul. Isto é, Moçambique não foge a regra de ser um país em desenvolvimento que exporta produtos brutos e importa produtos manufacturados da Índia. E, apesar da economia indiana apresentar uma estrutura bastante robusta com alguns sectores a usarem tecnologia de ponta como o caso de informática, ela ainda é considerada uma economia em desenvolvimento. Em todo o caso, pode -se afirmar que apesar da Índia e Moçambique pertencerem ao grupo dos países do Sul, a relação comercial compadece com as trocas comerciais entre o Norte e Sul. Contudo a balança comercial favorável para Moçambiquenos últimos anos é bastante benéfico para os investimentos no sector agrícola, esta que por sua vezé a base da sua economia, e melhorar a produtividade neste sector.

\section{A relevância do Investimento Indiano em Moçambique}

A grande parte do investimento indiano decorre da na área de indústria extractiva mais concretamente no sector do carvão e gás natural nos últimos anos. Porém, os investimentos nos outros sectores não deixam de ser importantes pois, estão alocados em diversas áreas e em diferentes distritos do país. Para melhor perceber a dimensão dos investimentos indianos em Moçambique, traz-se primeiro os investimentos no sector não extractivo seguido do investimento no sector extractivo. Moçambique é o país que mais recebe investimentos indianos no continente africano seguido de Maurícias. E, a tendência demonstra contínuo crescimento do investimento indiano em Moçambique.

\section{Investimento no Sector Não Extractivo}

No período compreendido entre 2009 a 2019, o governo de Moçambique aprovou 123 projectos indianos. Como resultado, foram criados cerca de 21.133 postos de trabalho, envolvendo investidores privados da Índia, no valor total de US\$ 659.181.213 como se pode observar na tabela 2 abaixo. 
Tabela 2 - Número de Projectos, Emprego e Investimento (2009-2019)

\begin{tabular}{llll}
\hline Ano & No de Projectos & Emprego & Total (US\$) \\
\hline 2009 & & & 228.741 .035 \\
2010 & 6 & 2237 & 56.500 .583 \\
2011 & 11 & 3.048 & 96.043 .783 \\
2012 & 9 & 3.581 & 47.281 .000 \\
2013 & 11 & 1.202 & 20.165 .878 \\
2014 & 14 & 1.178 & 28.818 .647 \\
2015 & 15 & 1.639 & 81.627 .766 \\
2016 & 6 & 4.096 & 28.801 .613 \\
2017 & 16 & 1.683 & 5.643 .967 \\
2018 & 15 & 597 & 55.103 .719 \\
2019 & 17 & 1.472 & 10.453 .222 \\
Total & 3 & 400 & $\mathbf{6 5 9 . 1 8 1 . 2 1 3}$
\end{tabular}

Fonte: Centro de Promoção de Investimentos de Moçambique (2019).

A tabela 2 apresenta uma variação gradual dos investimentos ao longo dos anos com descidas bruscas como aconteceu no ano de 2017 mas com aumento no ano seguinte. Porém, o ano de 2017 foi o ano com menor investimento que não ultrapassou o valor de 6 milhões de dólares. Os investimentos indianos em Moçambique possuem várias vantagens. Em primeirolugar, os investimentos em sectores não extractivos como a agricultura e agro-indústria são estratégicos para economia do país uma vez que a agricultura é a base da economia Moçambicana e onde está empregue a maior parte da população. Em segundo lugar, a maior arte da população vive nas zonas rurais, o que dá uma grande relevância aos investimentos neste sector produtivo pois, a agro-indústria ajuda a aumentar a produtividade agrícola. Por último, a Índia possui também o clima semelhante à Moçambique, o que permite a adaptação das suas tecnologias agrícolas.

Portanto, pode-se afirmar que o investimento no sector não extractivo é de extrema importância para o desenvolvimento de Moçambique. Ademais, a Índia possui grande habilidade na produção de tecnologias de baixo custo para zonas rurais o que é uma mais -valia para Moçambique sendo um país de renda baixa.

\section{Investimento no Sector Extractivo}

A parceria entre Índia e Moçambique no sector extractivo está orientada pelas capacidades e interesses dos dois parceiros. Moçambique é um país rico e abundante em recursos naturais e energéticos como o gás e carvão. A Índia, por sua vez, é uma nação com défice energético ${ }^{5}$ que tem aumentado com o seu crescimento económico pujante. Conjuntamente, com este défice e, o aumento das ameaças ambientais houve um incremento da necessidade de energias menos poluidoras por parte da Índia. Neste contexto, a energia sob forma de gás tornou-se um factor importante para os investidores indianos.

Observa-se que apesar das tentativas da diversificação do uso dos recursos energéticos, a Índia ainda contínua altamente dependente do carvão. Os investimentos indianos no sector em Moçambique são de longa data, devido a demanda de carvão na Índia que é histórica. Sendo assim, esta dependência da maior relevância a relação entre os dois

\footnotetext{
${ }^{4}$ Dados do I semestre de 2019

${ }^{5}$ Em petróleo e gás natural
} 
países pois a Índia ainda apresenta índices elevados de consumo e, com previsão de aumentar ainda mais na próxima década de 2030. Neste sentido, este país ofereceu o crédito para assistência a Moçambique com vista incrementar a produção e exportação para a Índia. E, como se pode observar na tabela 3, um dos produtos mais exportados por Moçambique é o carvão atingindo $47 \%$ do total das exportações para a Índia.

Tabela 3 - Produtosmais Exportados por Moçambiquepara Índia

\begin{tabular}{lc}
\hline Produto & Percentagem \\
\hline Coque e semi-coque de carvão, Ligne., Turfa; retorta de carbono & $47 \%$ \\
Carvão pulverizado ou não, não aglomerado & $26 \%$ \\
Vegetais & $9 \%$ \\
Produtos químicos diversos & $6 \%$ \\
Frutas e nozes, excepto oleaginosas, frescasou secas & $4 \%$ \\
Outros & $6 \%$
\end{tabular}

Fonte: Elaborado pelas autoras com base em dados obtidos no UNCTAD (2018).

No sector da mineração do carvão, a International Coal Ventures Private, $L t d .{ }^{6}$, adquiriu em 2014, 65\% das acções da empresa brasileira Rio Tinto que explorava o carvão na província de Tete em Moçambique. Existem outras empresas indianas com presença também neste sector tais como a $J S P^{7}, J S W^{8}$, Coal India Ltd, Tata Steel, Essar, Midwest Africa, Sunflag group entre outras (KRISHNER, 2015).

Para facilitar a exportação do carvão para a Índia bem como ampliar a carga transportada, de 82 milhões de toneladas para 110, o grupo indiano Mozambique Essar Ports iniciou a construção da primeira fase do terminal de carvão com uma capacidade de 10 milhões de toneladas/ano no porto da Beira, província de Sofala no Centro de Moçambique, com um investimento de 260 milhões de dólares de um total de 440 milhões (FREY, 2018). Este é um projecto com uma concessão de 30 anos com possibilidade de extensão para mais 10 anos. Porém, a segunda fase irá depender do sucesso da primeira.

Apesar do porto do Beira ter limitações em termos de capacidade, de apenas receber navios com menos de 2 metros de profundidade e 50 mil toneladas de carga, ainda não é um factor negativo para as exportações para Índia pois, a distância entre as zonas de mineração e o porto de Beira é de $580 \mathrm{Km}$ enquanto o porto profundo de Nacala é de $912 \mathrm{Km}$ (FREY, 2018). Como se vê, a distância é um factor que tem impacto no custo de transporte e nas decisões de investimento indiano. Outro factor que beneficia as empresas indianas no sector do carvão é o acesso directo que Moçambique tem ao Oceano Índico. Portanto, como se pode observar, com o aumento da demanda de carvão, o acesso a um porto com terminal de carvão próximo da área de mineração, torna Moçambique estratégico para o investimento das empresas indianas.

No sector do gás natural, foram descobertas em Moçambique, no início de 2010 grandes, reservas de gás natural no Norte de Moçambique denominado Rovuma Basin. Assim, com o descobrimento das reservas de gás inicia -se uma nova fase nas relações de investimento entre Índia e Moçambique. As empresas indianas como o Oil and Gas Company (ONGC) Videsh $L t d^{9}$ e a Oil India Ltd adquiriram 20\% de participações na área 1 da Bacia de Gás do Rovuma, como apresentado no mapa 1 abaixo, por USD 5.07 Biliões em adição aos $10 \%$ que já pertenciam a Bharat Petro Resources Ltd., desde 2008.

\footnotetext{
${ }^{6}$ Um consórcio com 5 empresas indianas nomeadamente Steel Authority of India Limited (SAIL), Rashtriya Ispat Nigam Limited (NMDC), National Mineral Development Corporation Limited (RISL), National Thermal Power Corporation Limited (NTPC) e Coal India Limited (CIL).

7 Jindal Steel \& Power.

s Jindal South West.

9 Também denominada de OVL, Lda.
} 
A área 1 da Bacia do Rovuma apresentada no Mapa 1 ocupa cerca de $10.000 \mathrm{Km} 2$ e está localizado mais a norte da Bacia do Rovuma. A área 1 representa uma das maiores descobertas de gás offshore no Este de África e Moçambique temo potencial de se tornar um dos maiores centros mundiais produtores de LNG que segundo Prakash (2018), consiste em 2.1 triliões de metros cúbicos de gás acessível.

$\mathrm{Na}$ atualidade, a área 1 da Bacia do Rovuma estava a ser explorada pela empresa francesa Total com $26.5 \%$ de interesse participativo. O Contrato de Concessão para Pesquisa e Produção foi assinado a 1 de Dezembro de 2006 com a empresa Norte Americana Anadarko, tendo as actividades de pesquisa levado à descoberta de gás natural do Campo Golfinho/Atum na ordem de 31.3 Triliões de pés cúbicos. Mais tarde a Anadarkovendeu a sua participação a empresa Total em 2019. São parceiros da Total neste contrato de Concessão, a Empresa Nacional de Hidrocarbonetos $\left(\mathrm{ENH}^{10}\right)$, com $15 \%$ de interesse participativo, a Mitsui E\&P Mozambique Área 1 do Japão, com 20\%, a Oil and Natural Gas Corporation of India $(\text { ONGC })^{11}$ com 10\%; Bharat Petro Resources ${ }^{12}$ com 10\% e Oil India Limited ${ }^{13}$ também com 10\% e finalmente a PTTEP MozambiqueÁrea 1 da Tailândia com 8.5, (INSTITUTO NACIONAL DO PETRÓLEO, 2019).

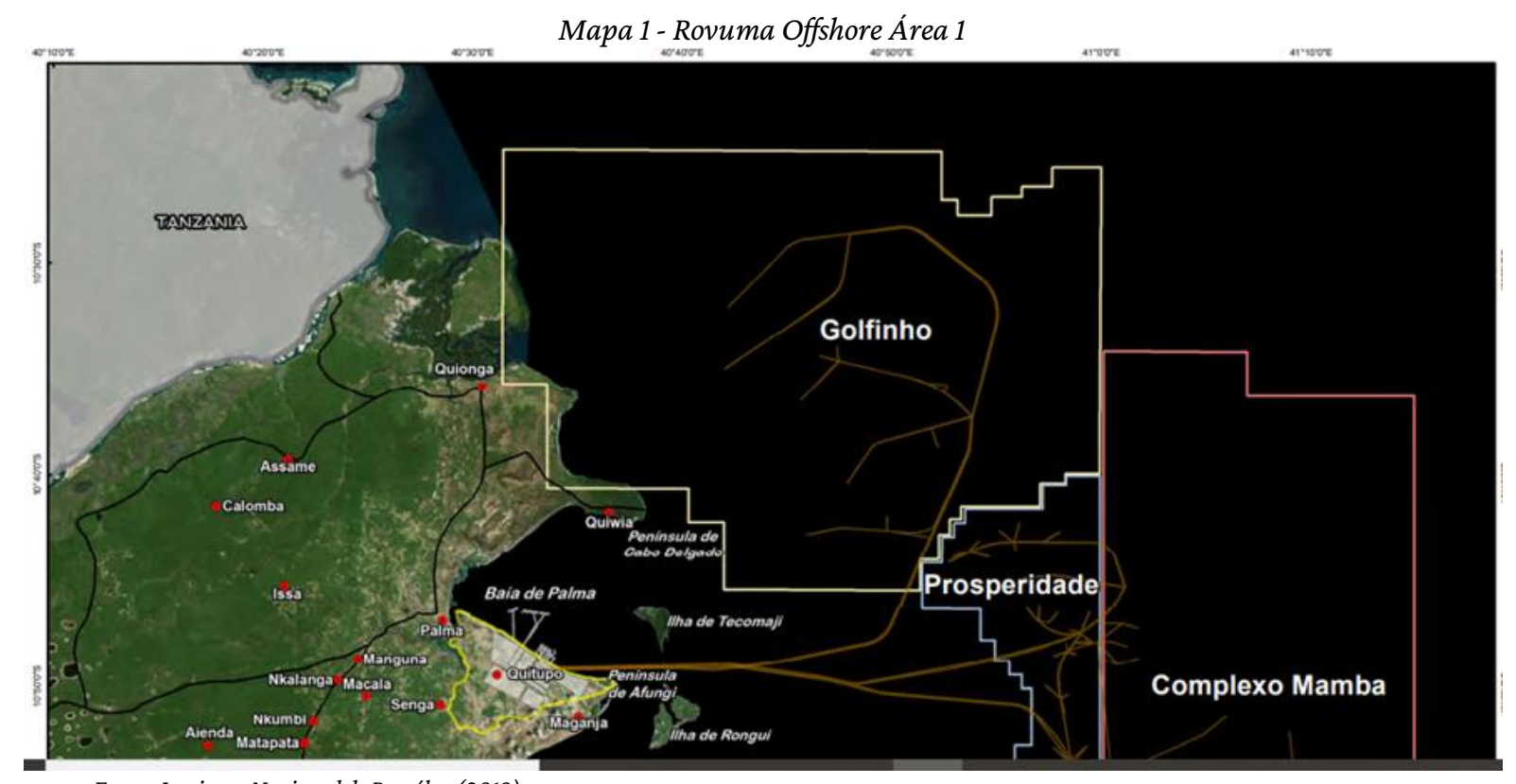

Fonte: Instituto Nacional de Petróleo (2019).

Para exploração da área 1 da Bacia Rovuma, os parceiros indianos conjuntamente com a Total irão investir um total de 22 a 24 bilhões de USD para desenvolver o campo e construir unidade de liquefacção de gás natural de 12,88 milhões de toneladas para vender a consumidores estrangeiros. Um investimento adicional de USD 7.8 bilhões é esperado para ser investido pelas empresas indianas. Mais uma vez, devido a sua localização estratégica Moçambique favorece aos investimentos das empresas indianas que terão a vantagem de exportar o gás natural através dos portos. $\mathrm{O}$ desenvolvimento do Rovuma seria uma fonte alternativa de LNG para a Índia, que levaria apenas 7 dias a ser transportado de Moçambique para os portos nortenhos da Índia (PRAKASH, 2018).

No total, as três empresas indianas com participação do Estado detêm $30 \%$ dos direitos de exploração do gás no bloco da área 1. Estas empresas já investiram cerca de USD 6.5 biliões nos campos de Gás do Rovuma. Este investimento avultadoé o resultado da política de energia renovável que por sua vezé o pilar do programa massivo de energia limpa da Índia, pelo qual a Índia prevê atingir 175.000 MW da capacidade instalada da energia renovável até 2022. Sendo assim, $\mathrm{O}$

\footnotetext{
Empresa Estatal Moçambicana.

Uma filial integralmente detida da Oil and Natural Gas Corporation (ONGC), a empresa nacional de petróleos da Índia, e a maior empresa internacional de pesquisa e produção de petróleo e gás desse país.

12 Empresa estatal de petróleos e gás, incluída na lista Fortune Global 500 e com sede em Mumbai.

13 A segunda maior companhia de petróleo e gás da Índia.
} 
investimento indiano em Moçambique está previsto para atingir USD 13 Biliões por volta de 2028. Ainda mais, prevê-se que em 2020 as empresas indianas invistam em infra -estruturas para importação de gás natural no país (PRAKASH, 2018). Esta convergência de energia entre as duas nações promove parceria estratégica entre os dois países.

Portanto, pode se observar a presença de investimentos volumosos que a Índia está a realizar nos sector energético como o de carvão e gás natural. Ainda mais, os mesmos têm uma perspectiva de investimento contínuo para próximas décadas. Por fim mencionar a importância dos assinatura de acordos e memorandos de entendimentos que permitem melhorar a cooperação na área de Gás natural.

Entretanto, assim como no comércio, a china continua sendo um grande concorrente da Índia em Moçambique. Esta afirmação também é coadjuvada pelo Yadav (2014), que assegura que a China é o principal competidor da Índia no continente africano onde a sua presença é quase o dobro da Índia. A China se encontra na lista de principais investidores em Moçambique desde 2016 superando os investimentos Indianos como apresentado na tabela 4:

Tabela 4 - Investimento Directo Estrangeiro da China vs Índia em Moçambique (Valor em USD)

\begin{tabular}{lll}
\hline Ano & China & Índia \\
\hline $\mathbf{2 0 1 4}$ & 44.811 .985 .54 & 4.298 .128 .73 \\
$\mathbf{2 0 1 5}$ & 52.251 .894 .45 & 459.556 .763 .97 \\
$\mathbf{2 0 1 6}$ & 33.466 .825 .04 & 4.420 .678 .39 \\
$\mathbf{2 0 1 7}$ & 222.427 .764 .09 & 2.996 .730 .22 \\
$\mathbf{2 0 1 8}$ & 26.305 .781 .56 & 1.742 .376 .73 \\
\hline
\end{tabular}

Fonte: Elaborado pela autora a partir dos dados de Banco de Moçambique(2019).

A tabela 4 acima apresenta uma clara vantagem da China sobre Índia em Moçambique principalmente pelos investimentos nos sectores de infra-estruturas. Contudo, a aproximação cada vez maior da China poderá trazer vantagens para Moçambique pois, a competição entre as duas potências pode ser sinónimo de maior poder de negociação para o país. E, sendo Moçambique estratégico para os interesses da Índia, esta última terámaior atenção na sua cooperação e apoio.

Para além da procura de recursos e mercado, o aumento da presença chinesa em Moçambique se enquadra no plano One Belt One Road Initiative, lançado em 2014. Esta iniciativa pretende conectar a China ao mercado da Europa e África. Ela conta com uma série de bases aéreas e navais, portos comerciais e centros de inteligência estrategicamente posicionados que irão ameaçar directamente os interesses da Índia na região do Oceano Índico. O plano da China inclui estender seus interesses económicos até a Europa por duas vias, passando pela Ásia do Norte, Leste de África e Médio Oriente.

Resumindo, a China ocupa uma posição de liderança no sector de investimento em Moçambique porém, a Índia ocupa posição privilegiada em relação a China no sector comercial, onde para além de ocupar a posição de topo nas exportações Moçambicanas possui uma balança comercial positiva. Entretanto, apesar do avanço massivo da China em Moçambique, a Índia leva a vantagem de partilhar uma história e cultura comum através da sua presença milenar.

\section{Outros investimentos}

As linhas de crédito são outra forma de investimento indiano em Moçambique pois, pretendem impulsionar a entrada de empresas e produtos indianos no país uma vez que as regras de acesso estipula que 75\% dovalor aprovado deve ser usado para adquirir produtos provenientes da Índia. Na base da tabela 5 abaixo pode -se verificar que Índia já cedeu mais de 700 milhões de dólares americanos através das linhas de crédito a Moçambique: 
Tabela 5 - Linhas de Crédito Aprovadas Para Moçambique

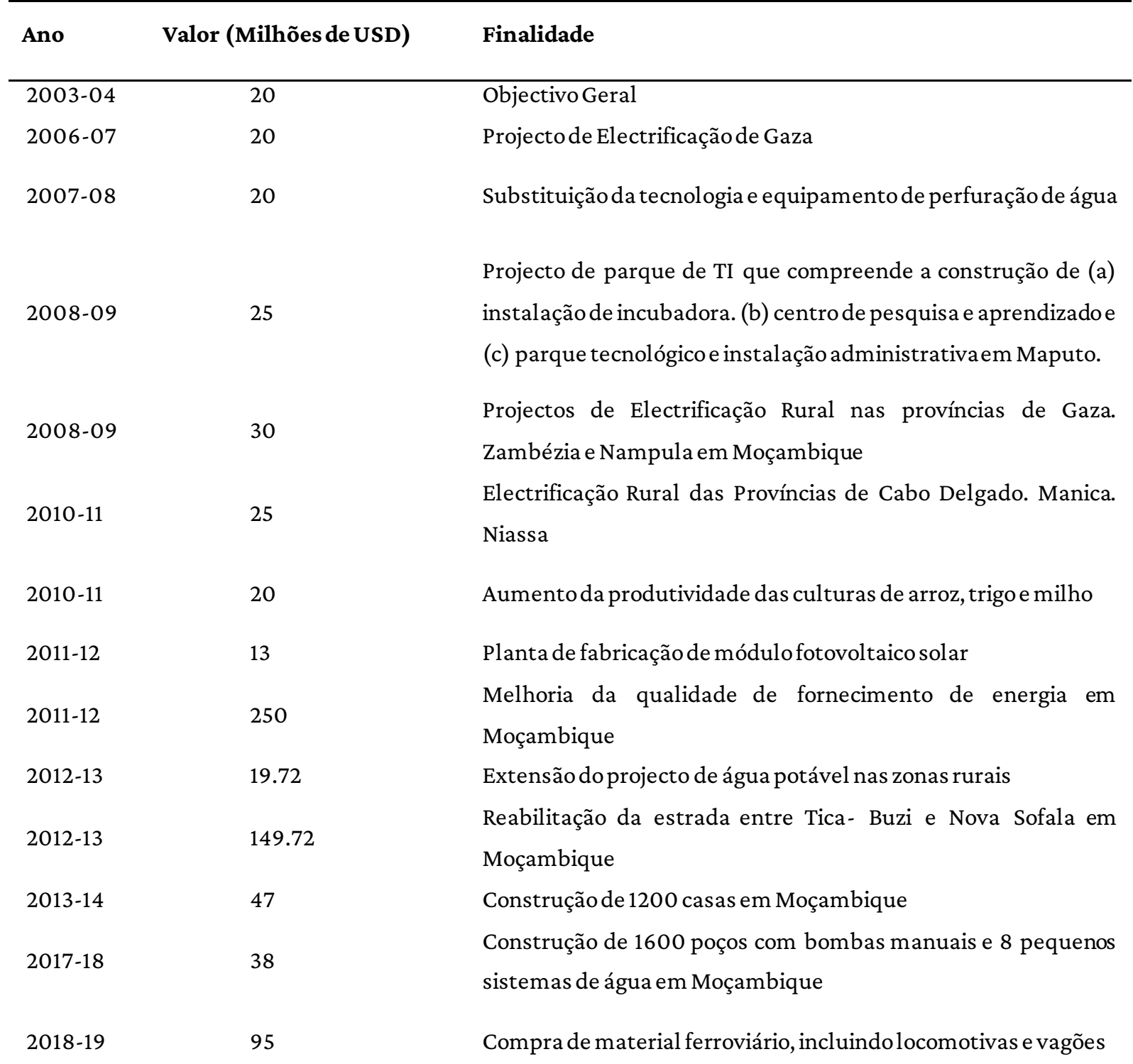

Total: 722.4

Fonte: Elaborado pelas autoras a partir de dados obtidos pelo EXIM Bank of India (2019).

Os investimentos variam de sector como se observa na tabela 5 acima. Os mesmos vão para o aprovisionamento dos furos de água, aumento da produtividade agrícola, melhoria e distribuição de electricidade, reabilitação de infra estruturas deirrigação, construção de parque de informática e reabilitação de estradas. As linhas de crédito apesar de terem como principal objectivo impulsionar as empresas indianas através da compra do seu equipamento ou instalação do mesmo, também ajudam na transferência de tecnologia. A título de exemplo, temos o Parque de Ciência e Tecnologia que consiste numa infra-estrutura de apoio, tal como terreno infra-estruturado, edifícios e serviços de gestão, para o estabelecimento e o desenvolvimento de empresas baseadas no conhecimento, localizadas num ambiente ligado a centros de investigação e tecnologia de excelência, tais como instituições de ensino superior e Instituições de Investigação (MOÇAMBIQUE, 2019). Acrescido a este facto, o parque visa impulsionar o desenvolvimento nas áreas deinovação, ciência e tecnologia nas comunidades em que é implantado. É um lugar de produção, desenvolvimento e disseminação de conhecimento, entre academia, sector privado, sector público, sociedade civil e comunidade local. 
Este tipo de centro de excelência demonstra o interesse de partilha de tecnologia por parte da Índia para Moçambique, esta que tanto precisa de desenvolver este sector. Outrobenefício da cooperação e ntre Índia e Moçambique tem a ver com a semelhança das condições sócio-económicas de ambos pois, permite um maior entendimento das suas necessidades. Portanto, como se pode observar, as linhas de crédito podem ajudar a alavancar sectores vitais em Moçambique que foram destruídos durante o período da guerra civil.

\section{Cooperação no Sector de Segurança}

A cooperação entre Índia e Moçambique no sector de segurança inicia no período da guerra fria, onde Moçambique atravessava uma guerra civil levada a cabo pela Re sistência Nacional de Moçambique (RENAMO), um grupo apoiado pelo sistema de Apartheid da África do Sul e Ian Smith da Rodésia do Sul. Segundo Chaudhuri (2017), a marinha de guerra da Índia prestou assistência ao governo moçambicano no combate a Renamo no a no de 1986.

Outro ponto marcante neste sector aconteceu com o envio de 900 militares indianos para a missão da paz da Organização das Nações Unidas para Moçambique entre 1992-1994 denominada ONUMOZ (CHATURVEDI, 2015). Depois desta intervenção de sucesso, Moçambique passou a observar um período de estabilidade política. Outro momento em que a Índia se destaca na área de defesa foi o envio de navios militares para patrulhar o Canal de Moçambique durante duas grandes cimeiras realizadas no país. A primeira ocasião foi em 2003 quando Moçambique acolheu a cimeira da União Africana e em 2004 quando se realizou o fórum económico mundial. A Índia ainda ofereceu equipamentos e treinamento aos Serviços de Inteligência de Moçambique denominados SISE.

A cooperação prosseguiu em 2006 através de um Memorandum de Entendimento assinado na área de defesa e cooperação entre os dois países. Este documento prevê a cooperação nas áreas de técnica militar, apoio logístico e formação. No contexto deste Memorandum foi criado um grupo de trabalho conjunto de defesa. Porém, esta equipe, somente reuniu-se duas vezes até 2018 (PRAKASH, 2018). No entanto, factores como a localização geoestratégica de Moçambique na costa Este Africana e as aspirações Indianas em desempenhar um papel de lid erança noÍndico levaram a que se reactivasse o interesse deste grupo de trabalho conjunto de defesa que passou a reunir se com maior frequência.

Outro acordo na área de segurança foi assinado em 2012, que permite a Índia patrulhar as águas territoriais moçambicanas no Oceano Índico. No mesmo ano, a marinha naval indiana iniciou o patrulhamento anti-pirataria no Canal de Moçambique. Para além dos memorandos e da cooperação ao nível bilateral, a cooperação na área de defesa também toma forma pela cooperação Multilateral através da IORA e do Indian Ocean Naval Symposium ${ }^{14}$ (IONS) em que os dois países são membros. Já no ano de 2019, como apresentado no quadro 2 sobre os acordos assinados, o ministro da defesa indiana visitou Moçambique e seu homólogo também o fez no mesmo ano. A visita do ministro da defesa indiano a Moçambique resultou em dois memorandos nomeadamente, acordo sobre o compartilhamento de informações sobre White Shipping e outro sobre cooperação no campo da hidrografia, (FREY, 2019).

As visitas e os acordos assinados demonstram o interesse de ambas partes cooperarem no sector de segurança mas acima de tudo demonstra o interesse indiano em prover segurança marítima a Moçambique com o objectivo de obter acesso e controlo do Canal de Moçambique.

Como se pode observar pelos dados trazidos até aqui, Moçambique é um país estratégico para a Índia ao responder aos seus interesses geoestratégicos. A estratégia da China de One Ring One Belt que atravessa o Oceano Índico é mais um factor que contribui para a Índia "estrategizar” as suas alianças com Moçambique com vista a proteger o seu espaço de acção “natural”.

\footnotetext{
${ }^{14}$ É um fórum para aumentar a cooperação marítima entre os estados da região do Oceano Índico. O fórum é realizado bienalmente e ajuda a preservar as relações pacíficas entre as nações e, portanto, é fundamental para a construção de uma arquitectura de segurança marítima eficaz na região do Oceano Índico (AUSTRALIAN NAVY, 2020).
} 


\section{Conclusão}

As relações seculares entreÍndia e Moçambique têm ganhado ímpeto desde a descoberta de grandes reservas do gás natural no Norte de Moçambique. Ambos países demonstram interesse em aprofundar a sua cooperação em diferentes áreas desde política, económica, segurança e social. Apesar de ambos países apresentarem taxas de crescimento económico diferente, os dois possuem economias com características semelhantes de países em desenvolvimento.

Um dos factores que aproxima a Índia e Moçambique tem a ver com a complementaridade entre as suas economias que permite a aproximação entre os dois estados. A Índia necessita de recursos naturais tais como o carvão e gás natural e Moçambique possui ambos recursos em grande escala. Por seu lado, Moçambique necessita de parce iro comercial, acesso a tecnologia e investimento externo. Outro factor que aproxima estes dois estados é a conjuntural internacional em que a Índia se encontra. A sua aspiração em ter acesso e controle sobre o Oceano Índico colide com os interesses da China com a sua Estratégia One Belt One Ring que visa usar rota do Oceano Índico para exportar seus produtos. Ora, para a Índia, o OceanoÍndico é extremamente importante pois, é de onde ela importa a maior parte dos seus recursos energéticos e também usa para exportar seus bens. Neste contexto, a Índia está a aproximar se dos países banhados pelo Oceano Índico para obter parcerias com vista a ter acesso ao Oceano Índico.

Como demonstrado neste artigo, a Índia encontra-se entre os principais parceiros comerciais de Moçambique. E, um ponto extremamente revelante é que Moçambique possuibalança comercial positiva com esse país. Por seu turno, no sector de investimentos, Moçambique é o segundo país que mais recebe investimento indiano no continente Africano seguido de Ilhas Maurícias. A maior parte dos investimentos indianos em Moçambique vão para o sector energético carvão e gás natural. No entanto, os investimentos nos sectores não extractivos também são relevantes pois, criam oportunidades de emprego e criação de novos empreendimentos em Moçambique como apresentado na terceira parte do artigo.

Como referido anteriormente, as relações bilaterais não se cingem somente na área económica. O sector de segurança tem-se destacado nos últimos tempos devido aos interesses da Índia no acesso e controle do Oceano Índico mais especificamente do Canal de Moçambique. Esta é uma via estratégica para passagem de carga marítima contornando o Cabo da Boa Esperança e Moçambique tem uma localização privilegiadaneste ponto. Assim, a Índia tem envaidado esforço na promoçãode acordos neste sector bem como apoiologístico no que toca a segurança marítima para Moçambique.

Finalmente, importa referir que toda esta análise da relaçãobilateral entre Índia e Moçambique permite observar a aproximação entre os dois países em áreas importantes e demonstra como a Índia tornou -se num país estratégico para Moçambique. Analisando teoricamente a relação dos dois estados, podemos afirmar que a teoria da interdependência de Keohane e Nye Jr. (1977), que afirma que nenhum estadoé auto-suficiente para produzir todos os recursos de que precisa, se aplica a cooperaçãobilateral estabelecida entre Moçambique e a Índia, pois ambos os países precisam de recursos, tais como investimento externo, tecnologia e formação. Esta teoria ajudou também a comprovar que o descobrimento de reservas de gás natural permitiu o aprofundamento das relações bilaterais entre Índia e Moçambique. Além do mais, a presença secularda diáspora Indiana em Moçambique apesar de ser pequena encontra-se muitobem estabelecida aolongo do país que por sua vez ajuda no maior aprofundamento das relações destes dois países.

\section{Referências}

ALTO COMISSARIADO DA ÍNDIA. Relações Índia-Moçambique. Maputo, 2020. Disponível em: https://www.hcimaputo.gov.in/. Acesso em: 26 jun. 2020.

AUSTRALIAN NAVY. Indian Ocean Naval Symposium. Canberra, 2020. Disponível em:https://www.navy.gov.au/ions. Acesso em: 26 jun. 2020 .

BANCO DE MOÇAMBIQUE. Balança comercial de Moçambique. Maputo, 2019. Disponível em: http://www.bancomoc.mz/fm_pgLink.aspx?id=222. Acesso em: 1 mar. 2019. 
BUSSIÈRE, Matthieu; MEHL, Arnaud .China's and India's roles in global trade and finance: twin titans for the new Millennium? Frankfurt: European Central Bank, Jan. 2008. (Paper, 80).

CENTRO DE PROMOÇÃO DE INVESTIMENTOS DE MOÇAMBIQUE. Investimento indiano em Moçambique. Maputo, 2019. Disponível em: https://slideplayer.com.br/slide/5986390/. Acesso em: 20 mar. 2020.

CHAUDHURI, Pramit Pal. Framing India-Africa relations: narrative, platforms, areas. In: POSSI, R: GUENOUN, I. (Ed.). Securing the 21 ${ }^{\text {st }}$ century: mapping India-Africa engagement. 2017. p. 8-14.

DE SOUSA, Fernando. Dicionário de Relações Internacionais. Edições Afrontamento/ CEPESE - Centro de Estudos da População. Economia e Sociedade. Bloomington, 2005.

EXIM BANK OF INDIA. Financial products. Bombaim, 2019. Disponível em: https://www.eximbankindia.in/lines-of-creditGOILOC.aspx. Acesso em: 20 dez. 2019.

FREY, Adrian. Índia Mozambique relations. Club of Mozambique, Maputo, 2017. Disponivel em: http://clubofmozambique.com/news/Índia-mozambique-relations/. Acesso em: 2 abr. 2017.

FREY, Adrian. India, Mozambique sign 2 MoUs to strengthen defense cooperation. Club of Mozambique, Maputo, 29 July 2019. Disponivel em: https://clubofmozambique.com/news/india-mozambique-sign-2-mous-to-strengthen-defence-cooperation-138043/. Acesso em: 14 jan. 2020.

FREY, Adrian. Indian investment in Mozambique aims to reduce logistics cost for coal miners. Club of Mozambique, Maputo, 6 Feb. 2018. Disponível em: https://clubofmozambique.com/news/indian-investment-in-mozambique-aims-to-reduce-logistics-cost-forcoal-miners/. Acesso em: 12 mar. 2020.

GLOBAL EDGE. Mozambique trade statistics. East Lansing, 2019. Disponível em: https://globaledge.msu.edu/countries/mozambique/tradestats. Acesso em: 1 abr. 2017.

INDIA. Ministry of External Affairs. List of Agreements/MoUs signed during the visit of President of Mozambique to India. New Delhi, $\quad 5 \quad$ Aug. $2015 . \quad$ Disponível $\quad$ em: https://www.mea.gov.in/bilateraldocuments.htm?dtl/25572/list+of+agreementsmous+signed+during+the+visit+of+president+of+mozambique+to+india. Acesso em: 15 Janeiro 2020.

INSTITUTO NACIONAL DO PETRÓlEO (Moçambique). Mapas. Maputo, 2019. Disponível em: http://www.inp.gov.mz/pt/Mapas/Concessoes-Activas2. Acesso em:19 nov. 2019.

KIRSHNER, Joshua. India is helping Mozambique meet its energy needs: in good ways and bad. The Conversation, [s.l.], 23 Nov. 2015. Disponível em: http://theconversation.com/india-is-helping-mozambique-meet-its-energy-needs-in-good-ways-and-bad-50788. Acesso em: 4 set. 2019.

KEOHANE, Robert e NYE, Jr. Joseph S. Power and Interdependence; 4a Edição. Longman Ed.USA ,1997.

MOÇAMBIQUE. Ministério da Ciência e Tecnologia. Parque Tecnológico de Maluana. Maputo, 2019. Disponível em: http://ns.mct.gov.mz/mctestp/?q=content/parque-da-ci\%C3\%AAncia-e-tecnologia-de-maluana. Acesso em: 10 Janeiros 2020.

PRAKASH, Surya. Celebrating 43 years of independence of Mozambique: diplomacy and beyond. [S.l.], 2018.

UNITED NATIONS CONFERENCE ON TRADE AND DEVELOPMENT. World investment report. Geneva, 2019. Disponível em: https://unctad.org/en/pages/PressRelease.aspx?OriginalVersionID=461. Acesso em: 5 jul. 2020.

UNITED NATIONS CONFERENCE ON TRADE AND DEVELOPMENT. World investment report. Geneva, 2018. Geneva, 2018. Disponível em:https://unctadstat.unctad.org/wds/TableViewer/tableView.aspx?ReportId=24738. Acesso em: 12 mar. 2020.

\begin{tabular}{ll}
\hline Funçães de colaboração exercidas & \\
\hline Jacqueline A. Haffner: & Conceituação; Metodologia; Validação; Curadoria de dados; Administração do projeto; Análise formal; Obtenção de \\
Hetalben H. Patel: & Conceituação; Validação; Curadoria de dados; Investigação; Escrita (primeira redação); \\
\hline
\end{tabular}

